\title{
Fouling and clogging surveillance in open loop GSHP systems
}

\section{A systematic procedure for fouling and clogging detection in the whole groundwater circuit}

\author{
Sondre Gjengedal ${ }^{1} \mathbb{D} \cdot$ Randi K. Ramstad $^{1} \cdot$ Bernt O. Hilmo $^{2} \cdot$ Bjørn S. Frengstad $^{1}$
}

Received: 29 August 2018 / Accepted: 28 May 2019 / Published online: 21 June 2019

(C) The Author(s) 2019

\begin{abstract}
Fouling and clogging are some of the major water quality problems encountered in open loop ground source heat pump (GSHP) systems and aquifer thermal energy storage (ATES) systems. Here we present a surveillance strategy that can detect if and identify where in the system fouling and clogging might be developing without having to shut off the heat pump. In the presented system design, the test requires a minimum of four temperature sensors and two pressure sensors to describe the performance of the four major heat source system components, namely, the production well, the injection well, the submersible pump and the groundwater heat exchanger. The surveillance procedure involves conducting a step-test with incremental increases in the groundwater flow rate while measuring the pressure and temperature responses in the system components. The performance of the newly constructed installation functions as a baseline for future tests. By conducting the test systematically during operation an altered performance of the system can indicate clogging or fouling issues. Even though the cause of the problem must be identified through other means, the surveillance procedure presented here allows the operator to plan necessary maintenance and avoid critical damage to the heat source system.
\end{abstract}

Keywords Open loop GSHP systems $\cdot$ Aquifer $\cdot$ Fouling $\cdot$ Clogging $\cdot$ System performance surveillance $\cdot$ Step-test

\section{Introduction}

Groundwater quality is an important factor in open loop ground source heat pump (GSHP) installations (Bakema 2001; Banks 2012; Rees 2016). Chemical reactions, suspended soil particles and/or microbial growth in the water can cause a wide range of problems for the system. These problems can involve corrosion, clogging and increased fatigue and erosion of the submersible pump, groundwater heat

Sondre Gjengedal

sondre.gjengedal@ntnu.no

Randi K. Ramstad

randi.kalskin.ramstad@ntnu.no

Bernt O. Hilmo

BerntOlav.Hilmo@Asplanviak.no

Bjørn S. Frengstad

bjorn.frengstad@ntnu.no

1 Department of Geoscience and Petroleum, Norwegian University of Science and Technology, Trondheim, Norway

2 Asplan Viak AS, Trondheim, Norway exchanger, well screen and pipeline as well as clogging of the aquifer formation. Usually the performance of the heat pumps and overall cost of the operation is affected by reduced heat production. However, in severe cases, the complications can lead to complete system failure.

In this paper we present experiences with fouling and clogging of open loop GSHP systems in Melhus, Norway. We first describe the effects of fouling and clogging on the four major affected components in the system, i.e. the production well, the injection well, the submersible pump and the groundwater heat exchanger. We then present a surveillance procedure for fault detection. The described surveillance procedure measures the system performance and, when applied systematically during operation, it can identify potential clogging or fouling issues in each of the four major components. The surveillance procedure is also valid for aquifer thermal energy storage (ATES) systems as well as relevant for groundwater wells for drinking water and industrial purposes.

Clogging and fouling of system components of GSHP systems is a commonly encountered problem in Melhus (Riise 2015; Brøste 2017). The main concerns are the chemical reactions that result in the precipitation of particles that subsequently accumulate on surfaces inside pumps, pipes, heat 
exchangers and other components in contact with the circulating groundwater. Since the buildup of particles occurs on surfaces that are not visible to the operator, the problems are often not predictable during normal system operation and undetected until a critical failure is imminent. The examples presented in this paper were discovered during maintenance checks when components such as pipes, well screens, submersible pumps or heat exchangers had failed and had to be repaired or cleaned. This approach is costly, not only because of the maintenance cost and downtime of the heat pump, but also because the heat pump operates at a lower coefficient of performance (COP) prior to failure.

The current GSHP systems in Melhus are not sufficiently equipped with sensors to detect the development of fouling and clogging problems. While some installations are now endeavoring to do so, there still exists a need for a procedure that can help the operator to distinguish normal system performance from the effects caused by fouling and clogging. If clogging and fouling can be detected at an early stage, the operator would be able to plan necessary maintenance and avoid critical damage to the heat source system.

\section{Background}

Within the concept of ground source heat, the open loop system differs from the more common closed loop system. The open loop system utilizes groundwater as a source of thermal energy by employing a heat pump coupled with a heat distribution system in the building. Groundwater wells in Norway are typically established in aquifers of unconsolidated sand and gravel deposit. This is also the case for the town center of Melhus in Norway. The Melhus aquifer has been utilized for heating and cooling purposes since 1999, which makes
Melhus a pioneering municipality in Norway in terms of open loop systems (Riise 2015). At the present time, the aquifer supplies nine building complexes with heat, and three of them with cooling as well.

There are two typical open loop GSHP system schemes in Melhus (Fig. 1). The heat pump system connects to the aquifer through a production well with slotted screens. The submersible pump is installed above the top of the well screen to minimize the risk of air entering the aquifer, which potentially could allow air bubbles to clog the well screen and the aquifer formation. Groundwater is pumped from the production well through a heat exchanger, where heat energy is extracted from the water by reducing its temperature. A temperature reduction of $3-4{ }^{\circ} \mathrm{C}$ is typical, but this depends on the heat demand in the building and often varies throughout the heating season. The two oldest GSHP systems dispose of the heat-exchanged groundwater to a nearby river through the local drainage system (Fig. 1a). The newer and more common systems re-inject the exchanged groundwater back into the aquifer through an injection well (Fig. 1b). Re-injection is deemed favorable because it helps maintain the water level in the aquifer.

Similar to other water heat sources, such as seawater or lakes, open loop GSHP systems are disposed to complications arising from water quality problems (Bakema 2001; Stene 2001). Typical problems can involve corrosion of components or different types of biological, chemical or mechanical clogging and fouling. The severity of the problems often depend on the on-site water quality, and a tap is often installed in the systems for groundwater quality sampling (Fig. 1). The groundwater in the Melhus aquifer has a brackish quality and contains more dissolved ions than does freshwater (Riise 2015; Brøste 2017). Thus, the open loop system design follows the same principles of some seawater heat pump systems in which an indirect system with an additional
Fig. 1 Two types of open loop ground source heat pump (GSHP) systems in Melhus. a Design solution with run-off to nearby river through the local drainage system, b most common design with reinjection of groundwater

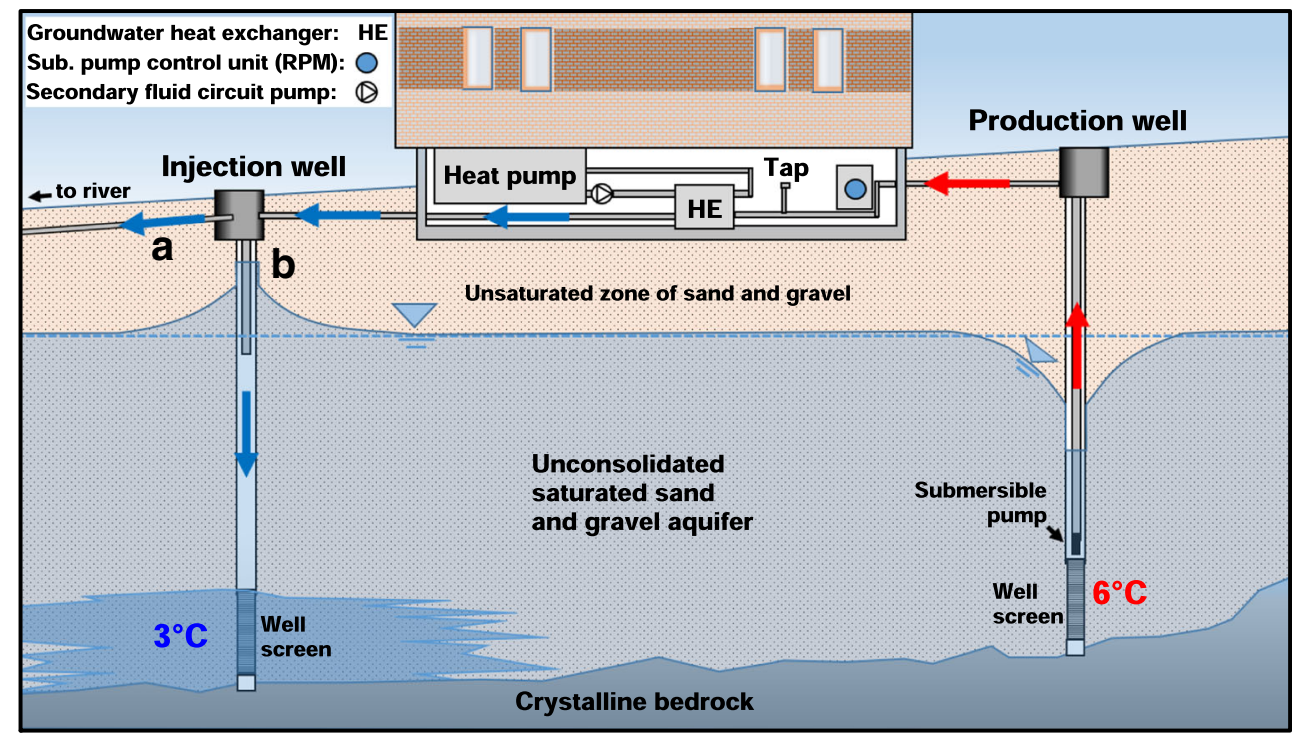


groundwater heat exchanger separates the heat pump unit from the groundwater (Fig. 1). The groundwater heat exchanger is customized to the particular water quality condition. This customization protects the evaporator from corrosion, fouling and freezing risks and will often be the most economical capital cost solution for the system. However, the additional heat exchanger has the disadvantages of lowering the $\mathrm{COP}$ of the system and increasing the operational costs (Stene 2001).

Precipitated hydroxide particles are present in all of the nine heat pump installations in Melhus. Water quality investigations have shown that high concentrations of dissolved iron and manganese occur naturally in the groundwater at levels of up to 5.78 and $0.68 \mathrm{mg} / \mathrm{l}$, respectively (Riise 2015; Brøste 2017). When exposed to an oxidizing agent, such as, oxygen in the air, dissolved iron and manganese ions readily precipitate as hydroxide particles. Thus, some of the fouling and clogging problems are deemed to be related to leakages of air into the heat source systems. Other possible causes might be related to alterations in groundwater $\mathrm{pH}$ through a loss of pressure and subsequent degassing of dissolved carbon dioxide, as discussed by Banks (2012) and Bakema (2001).

Fouling and clogging problems can be categorized into five major problem types in GSHP systems. Depending on the system design and water quality, one or more of the following problems might develop:

\section{Problem (1): Clogging of the production well screen leads} to reduced groundwater flow rate and a loss of well production capacity. Clogging of the screen causes the water level in the well to drop further than intended during pumping. If the water level in the well drops down to the pump, mixing of air into the system will become a major problem. Two such events have occurred in Melhus (Fig. 2a, b).

Problem (2): Clogging of the injection well screen leads to reduced groundwater flow rate and insufficient injection capacity. This development is the most commonly encountered problem, and all of the seven injection wells in Melhus have had clogging problems. The clogging material is often found to be a mixture of sand, silt and clays along with iron and/or manganese hydroxides. Microbial growth has been discovered in one injection well. Flooding on the surface has occurred where the clogging issue was severe.

Problem (3): Clogging in the aquifer. It is possible for particles to deposit in the aquifer formation itself. This is a problem discussed by Andersson et al. (1984) and Bakema (2001). The problem might develop if particles infiltrate through the injection well screen, allowing the particles to re-enter the aquifer and clog the pore-space in the sediments. The problem might also develop because of chemical reactions between the native groundwater and the injected groundwater with a different chemical composition. The clogging reduces the hydraulic conductivity of the aquifer locally and can affect the performance of the production well or injection well. There are registered two cases of aquifer clogging in Melhus.

Problem (4): Precipitation within pipes and other components of the GSHP systems narrows the crosssectional flow area and induces increased friction to groundwater flow through the system. The increased friction ultimately renders the submersible pump unable to supply enough water to the groundwater heat exchanger. Five of the open loop GSHP systems in Melhus have experienced such problems. On one occasion, a 1-cm-thick film of iron hydroxide coating was found during a maintenance check (Fig. 2c). If the friction losses become
Fig. 2 Iron hydroxide problems encountered in the open loop GSHP systems in Melhus. a Clogging of a production well screen, $\mathbf{b}$ damaged submersible pump, $\mathbf{c}$ old pipe section with 1$\mathrm{cm}$-thick film of iron hydroxide (photograph courtesy of Rolf Aune, Trondheim), $\mathbf{d}$ fouling in a plate heat exchanger

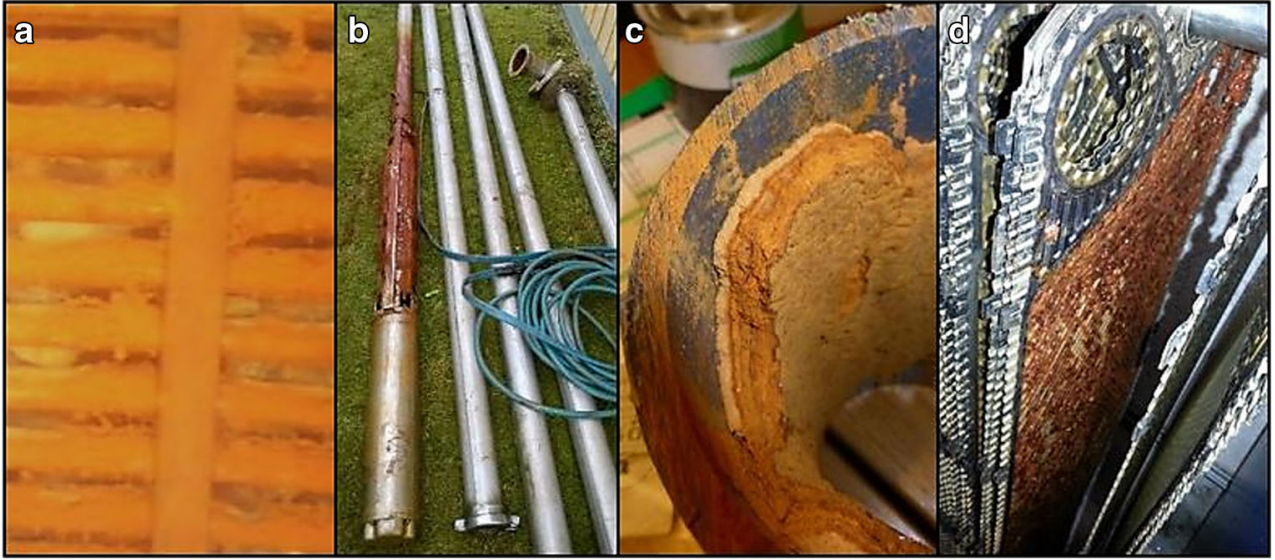


too high, the submersible pump will not operate reliably and can fail. This has occurred once in Melhus.

Problem (5): Particles deposit in the heat exchanger. The deposits not only cause increased friction to flow, but also function as insulation that reduces the heat transfer efficiency of the heat exchanger (Fig. 2d). Plate heat exchangers (PHE) are the preferred heat exchanger type in the GSHP systems in Melhus. Gasket PHE types can be opened for inspection and are often preferred over the brazed PHE types, but both types are used. Compared to other heat exchanger types PHEs are deemed to be reliable with respect to fouling because they are designed to operate within turbulent flow conditions (Melo et al. 1988; Stene 2001). Nevertheless, seven of the open loop GSHP system in Melhus have experienced heat exchanger fouling and clogging issues, typically caused by iron and/or manganese hydroxides.

\section{Common system control and surveillance strategies}

The heat pump units in open loop GSHP systems are controlled in order to produce enough heat to meet the heat demand in the building being serviced by the system. The demand varies throughout the year, with peak demands during the winter months and minimum demands during the summer months. The heat demand is transferred to the heat pump by controlling the heat extraction process from the groundwater heat exchanger. Typical control and instrumentation schemes are illustrated in Fig. 3. The secondary fluid pump is usually equipped with an on/off control and a constant flow rate. A variable speed drive (VSD) control unit typically controls the submersible pump in the open loop GSHP systems. This VSD control unit allows the system to adjust the rotational speed of the submersible pump motor (RPM), specifically in terms of its frequency $(\mathrm{Hz})$, which in turn adjusts the flow rate. Seven of the nine systems in Melhus operate the VSD at constant speeds. Consequently, these systems control the heat production rate through temperature variations in the groundwater heat exchanger. The remaining two systems operate the VSD according to the temperature of the heat-exchanged and injected groundwater. These latter two systems control the groundwater flow rate to maintain a fixed temperature in the temperature sensor denoted T3, typically $2-3{ }^{\circ} \mathrm{C}$ (Fig. 3 ). To minimize the risk of excessive pumping, one of the two systems simultaneously controls the flow rate according to the water level in the production well. The flow rate is reduced if the pressure level in the well drops below a predefined level in sensor p1 (Fig. 3).

As shown in Fig. 3, pressure (p1-p3) and temperature (T1T4) sensors are the main sensor types applied for system surveillance in Melhus because these are low cost and easy to fit. Some of the larger installations monitor the volume flow rate, but the overall cost of the sensors is probably the main reason why volume flowmeters (FL in Fig. 3 ) are absent in the smallcapacity $(\leq 100 \mathrm{~kW})$ open loop GSHP systems. These sensor types are common in many heat pump applications (Stene 2001; Rees 2016) and also commonly used for system surveillance in other industries and industrial applications, such as, for example, district heating applications, oil and gas industries (Melo et al. 1988; Müller-Steinhagen 2000) and food processing industries (Nema and Datta 2005).

None of the installations in Melhus follows a defined surveillance procedure with systematic data logging. Furthermore, the data provided by the sensors and instruments shown in Fig. 3 are inadequate because they fail to incorporate all of the relevant components in the system. Common to all the systems is a lack of pressure monitoring of the production well and the injection well. Only one system monitors the pressure in the production well, while none of the systems monitor the pressure in the injection well. Only four of nine installations monitor the volume flow rate, which is considered to be a vital parameter in open loop systems surveillance (Banks 2012; Rees 2016). The most common approach focuses on detecting fouling of the groundwater heat exchanger
Fig. 3 Schematic diagram of the principle components of the typical open loop GSHP system in Melhus with temperature sensors, pressure sensors and flowmeter. $V S D$ Variable speed drive

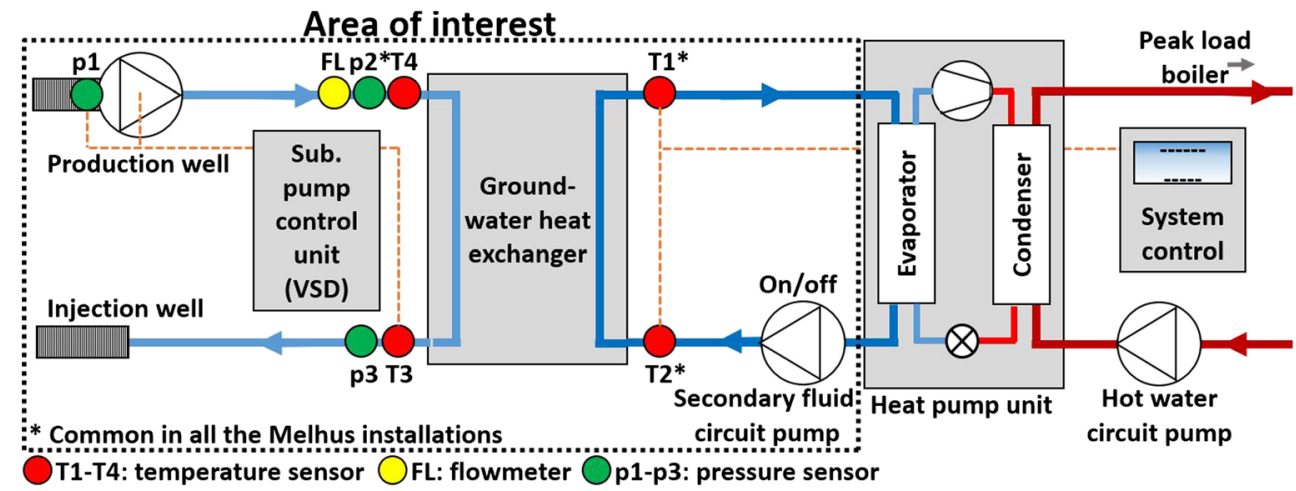


with pressure sensors $\mathrm{p} 2$ and $\mathrm{p} 3$. An increase in the differential pressure between pressure sensors $\mathrm{p} 2$ and $\mathrm{p} 3$ can indicate a potential fouling problem in the groundwater heat exchanger. However, pressure is dependent on the flow rate, and such data are often difficult to interpret without information from a flowmeter. This is particularly the case when the flow rate is highly variable, which can occur when the VSD controls the flow rate according to the return temperature of the heatexchanged groundwater (T3). Furthermore, only two of the nine installations in Melhus have included temperature sensors T3 and T4 into their system surveillance scheme.

\section{System performance}

Each of the five problems described in the Background section affect the performance of the open loop GSHP system in a distinctive way, and the respective effects are detectable if the system is equipped with the appropriate sensors and control equipment. The initial system performance must be understood, and there must also be an understanding of how fouling and clogging can change the initial performance. In this section we focus on explaining these changes and provide the necessary analytical tools for detecting fouling and clogging.

In the specific open loop GSHP system shown in Fig. 1, the design of the system limits the potential problems to an area of interest, as shown in Fig. 3. Within this area, the submersible pump and the secondary fluid circulation pump are active components that provide fluid flow through the groundwater heat exchanger. The heat exchanger can be termed an active component in terms of the flow of heat from one fluid to the other. The wells and the pipes can be termed passive components. Understanding the behavior of the pumps and the heat exchanger is important because they are affected regardless of where in the system fouling or clogging develops.

\section{Groundwater heat exchanger performance and fouling effects}

There are a large variety of different heat exchangers, and their respective performance is dependent on both design and materials. The overall performance of any heat exchanger can be described by heat rate Eqs 1-3 (Stene 2001; von Böckh and Wetzel 2012).

$Q_{w} \cdot \Delta T_{w} \cdot \rho C_{P w}=P$

$Q_{s f} \cdot \Delta T_{s f} \cdot \rho C_{P s f}=P$

$$
U \cdot A \cdot L M T D=P
$$

These equations are relevant for both heating and cooling operations. In heating mode, Eqs. (1) and (2) state that heat extracted from the groundwater, $\mathrm{P}(\mathrm{kW})$, is proportional to the groundwater flow rate, $Q_{w}(1 / s)$, the volumetric heat capacity of water, $\rho C_{\mathrm{Pw}}(\mathrm{kJ} / 1 \cdot \mathrm{K})$ and the temperature reduction of the groundwater, $\Delta \mathrm{T}_{\mathrm{w}}(\mathrm{K})$. The secondary fluid absorbs this heat, $\mathrm{P}(\mathrm{kW})$, and undergoes a corresponding increase in temperature, $\Delta \mathrm{T}_{\mathrm{sf}}(\mathrm{K})$, depending on the flow rate, $\mathrm{Q}_{\mathrm{sf}}(\mathrm{l} / \mathrm{s})$ and the volumetric heat capacity of the secondary fluid, $\rho \mathrm{C}_{\mathrm{Psf}}(\mathrm{kJ} / \mathrm{l}$. $\mathrm{K})$. The heat is transmitted through the steel plates in the heat exchanger, and the amount of heat in Eq. (3), P (kW), is equal to the heat extracted from the groundwater and absorbed by the secondary fluid in Eqs. (1) and (2), respectively. $\mathrm{U}\left(\mathrm{W} / \mathrm{m}^{2} \cdot \mathrm{K}\right)$ denotes the overall heat transfer coefficient of the heat exchanger, and $\mathrm{A}\left(\mathrm{m}^{2}\right)$ denotes the total heat transfer area in the heat exchanger. LMTD is the logarithmic mean temperature difference between the groundwater and the secondary fluid (Fig. 4). The LMTD is calculated from Eqs. (4) or (5) where $\Delta \mathrm{T}_{\mathrm{a}}$ denotes the temperature difference at the groundwater inlet of the heat exchanger and $\Delta \mathrm{T}_{\mathrm{b}}$ denotes the temperature difference at the groundwater outlet (von Böckh and Wetzel 2012).

$$
\begin{aligned}
& \text { LMTD }=\frac{\Delta T_{a}-\Delta T_{b}}{\ln \left(\Delta T_{a} / \Delta T_{b}\right)} \text { if } \quad \Delta T_{a}-\Delta T_{b} \neq 0 \\
& L M T D=\frac{\Delta T_{a}+\Delta T_{b}}{2} \quad \text { if } \quad \Delta T_{a}-\Delta T_{b}=0
\end{aligned}
$$

The overall heat transfer coefficient is a parameter that describes the rate at which heat flows from the groundwater to the secondary fluid. The rate depends on the individual heat transfer properties of the two fluids, as well as on the properties of the steel plate that separates them. During normal heat pump operation with constant groundwater

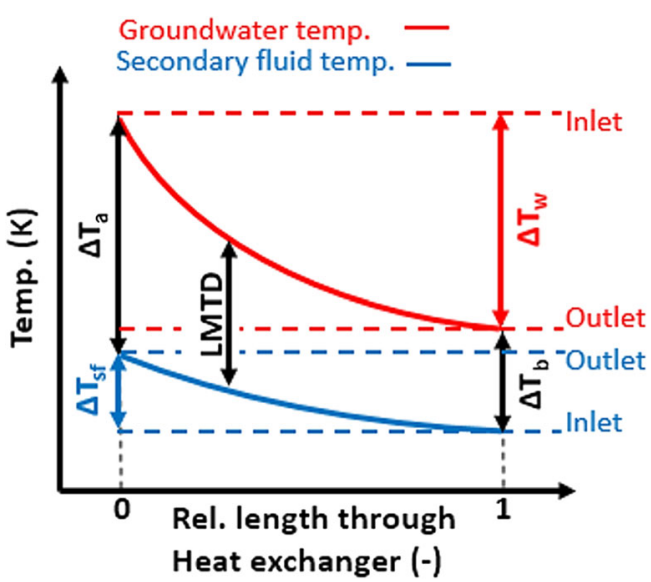

Fig. 4 Principle sketch of temperature development in the groundwater and the secondary fluid through a cross flow heat exchanger. LMTD Logarithmic mean temperature difference between the groundwater and the secondary fluid, $\Delta T_{s f}$ increase in termperature of the secondary fluid, $\Delta T_{w}$ temperature reduction of the groundwater, $\Delta T_{a}$ temperature difference at the groundwater inlet of the heat exchanger, $\Delta T_{b}$ temperature difference at the groundwater outlet 


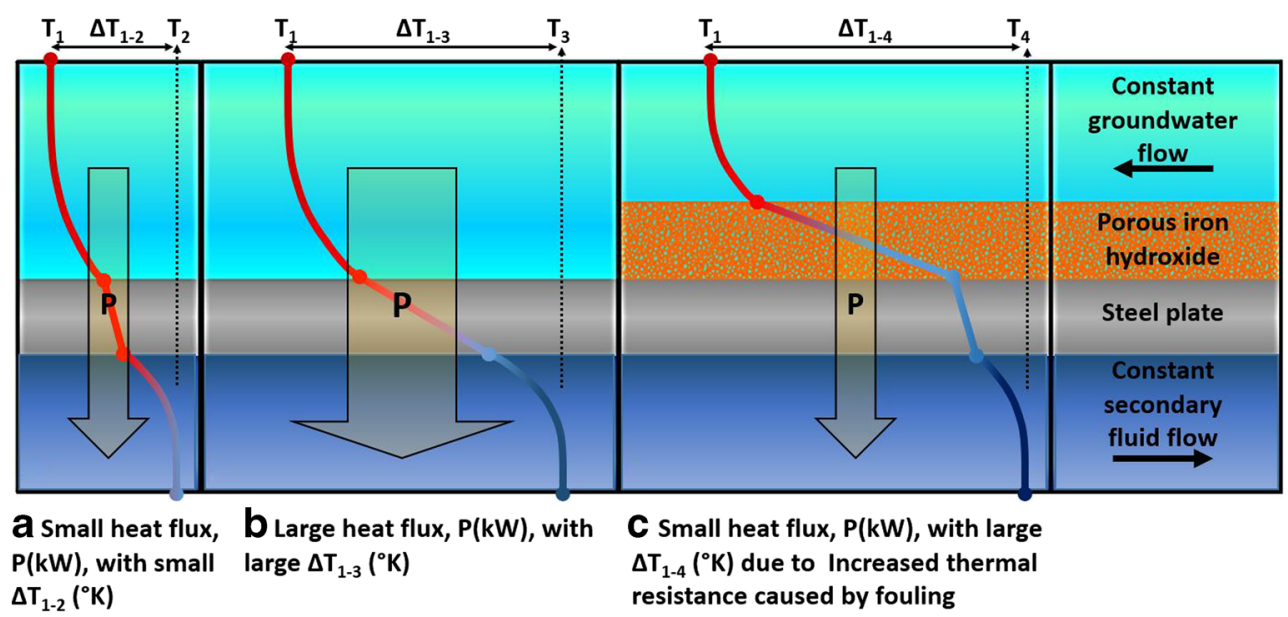

Fig. 5 Change of temperature profile and heat rate $(P$, in $\mathrm{kW})$, at a fixed location in a heat exchanger at constant groundwater flow rate and secondary fluid flow rate. a Small heat rate with small temperature difference $\left(\Delta T_{1-2}\right)$, b large heat rate with large temperature difference

flow rate and secondary fluid flow rate through the heat exchanger, the $U \cdot A$ value is constant, and the magnitude of the LMTD controls the heat flux. An increased temperature difference would result in an increase in the heat flux from the groundwater and an increase in heat production from the heat exchanger (Fig. 5a vs. b).

Fouling of the heat exchanger affects the overall heat transfer coefficient by adding an additional layer of material on the steel plate. The heat must travel through the deposited material; consequently, the thickness of the deposit and the thermal conductivity of the material determine its overall influence on the U.A value. Some deposits are porous and a certain amount of the fluid in which they deposited often fill the pore space. In such cases, the thermal properties of the fluid will affect the thermal properties of the deposit, and the fouling deposits will often have poor thermal conductivity $(\lambda ; \mathrm{W} / \mathrm{m} \cdot \mathrm{K})$. According to Atlas (2010), porous iron hydroxides $(\lambda=0.6 \mathrm{~W} / \mathrm{m} \cdot \mathrm{K})$ have a low conductivity compared to that of most metals, such as steel alloys $(\lambda=15-58 \mathrm{~W} / \mathrm{m} \cdot \mathrm{K})$. Fouling effectively reduces the U.A value of the heat exchanger. To maintain the same heat flux the temperature difference increases and compensates for the loss of the heat transfer coefficient in Eq. (3) (Fig. 5a vs. c). This means that a heat pump receives lower secondary fluid temperature at the evaporator inlet, which results in lower evaporation temperature and pressure. Depending on the type of heat pump working fluid, the lower suction pressure will reduce the COP of the heat pump by $2-$ $3 \%$ and the heating capacity by $3-4 \%$ for each $1 \mathrm{~K}$ increase in the LMTD (Stene 2001).

In many laboratory studies, such as that of Hasan et al. (2017), fouling is detected by monitoring the development of the U.A value over time by rearranging Eqs. (1) and (3) into Eq. (6). This approach is also common in industrial applications (Kerner 2011). A reduction of the U.A value
$\left(\Delta T_{1-3}\right), \mathbf{c}$ iron hydroxide precipitation on the steel effectively reduced the heat rate and an increased temperature difference $\left(\Delta T_{1-4}\right)$ is needed to maintain the same heat production from the heat exchanger

could mean that fouling is developing in the heat exchanger. Figure 6 illustrates a typical example of such a behavioral change where crystallization fouling reduces the heat transfer coefficient in a double pipe heat exchanger over a range of different flow rates.

$U \cdot A=\frac{P}{L M T D}=\frac{Q_{w} \cdot \Delta T_{w} \cdot \rho C_{P w}}{L M T D}$

Note the flow rate dependency of the $\mathrm{U}_{0}$ value, depicted in Fig. 6 with respect to Reynolds number, which is proportional to flow rate. The flow rate dependency of the heat transfer coefficient has practical implications for the heat exchanger in situations where clogging occurs outside of the heat exchanger, such as in the injection well only. In that case, the U.A value is reduced, and fouling or clogging

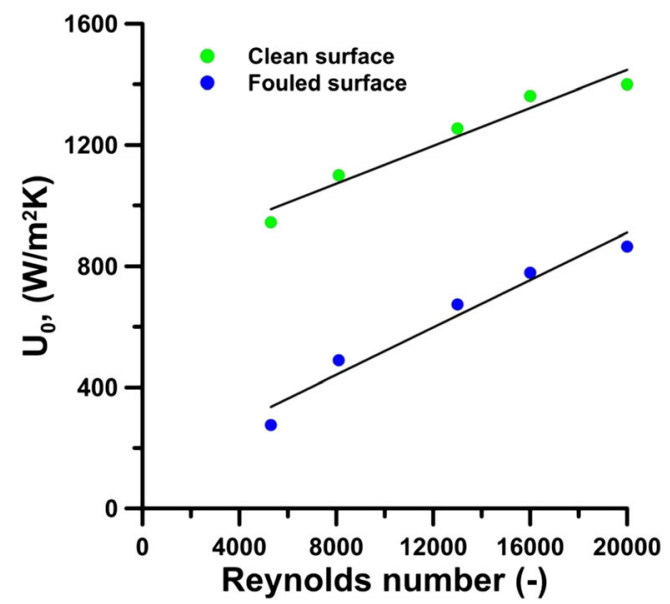

Fig. 6 Reduced heat transfer coefficient of a double pipe heat exchanger $\left(U_{0}\right)$ due to fouling (crystallization fouling effects). Modified after Hasan et al. (2017) 
of the passive components in the open loop system affects the groundwater heat exchanger indirectly through reduced flow rates.

\section{Pump performance and clogging effects on the groundwater flow rate}

Pump performance curves are specified by pump manufacturers, and these curves specify the range of operations suitable for the pump. The submersible pump should ideally be selected so that it operates at or close to the Best Efficiency Point (BEP) (Mackay 2004; Gülich 2014). This is achieved by selecting a submersible pump whose pumping curve intersects the system characteristics curve at the designed flow rate (Fig. 7). The system characteristics curve represents the energy needed to move groundwater through the system. The friction induced to the groundwater flow by the system components are flow dependent, and the required energy to move the fluid increases with increasing flow rate. Thus, a pump is selected to fit a specific system design. If the system characteristics change with time, the pump performance is affected. Generally, the manufacturers recommend operating the pump within the range of 70 to $120 \%$ of the BEP; outside this range the pump will not operate reliably (Mackay 2004).

In the case of fouling or clogging, the system characteristics change with time and induce increased friction to flow, for example, by reducing the internal diameter of a pipe (Fig. 2c). The system curve moves to the left of the BEP and the system characteristics curve will intersect the pumping curve progressively further away from the initial design point, which results in reduced flow rates (Fig. 7). There are increased risks associated with minimum flows, such as suction recirculation or discharge recirculation, two phenomena with similar

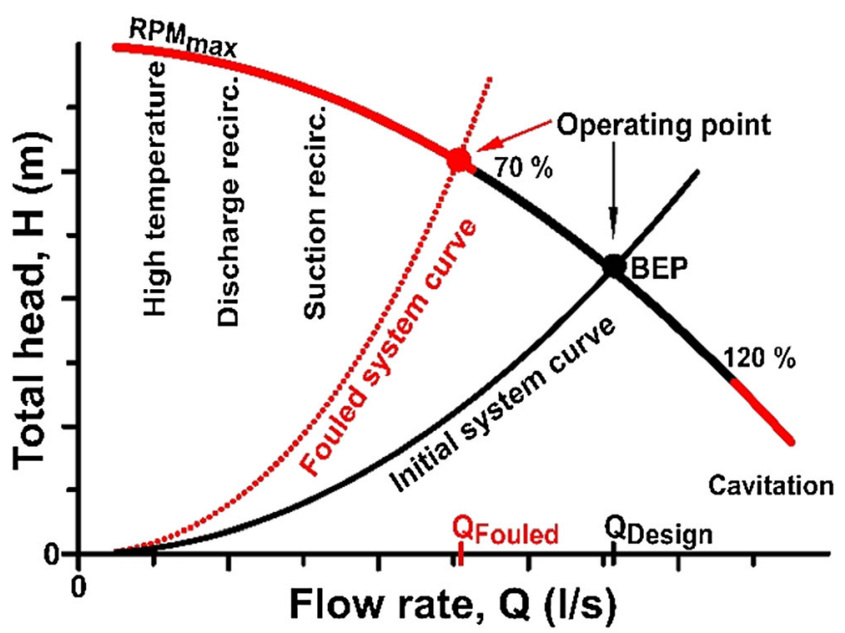

Fig. 7 Single pump performance curve $\left(R P M_{\max }\right)$ with risk areas highlighted in red along the curve. Fouling and clogging of system components increase the hydraulic friction, which results in lower flow rates and less reliable operating conditions. BEP Best Efficiency Point. Modified after Mackay (2004) symptoms to cavitation. These risks involve damage to the seals and bearings as well as increased fatigue and erosion on the impeller and shaft. At very low flow rates the risks associated with high temperatures and insufficient cooling of the pump motor also come into effect (Mackay 2004).

The system characteristics curve incorporates a combination of hydrostatic and hydrodynamic losses, often referred to as head losses. The hydrostatic head, $\mathrm{H}_{\text {stat }}(\mathrm{m})$, represents the pressure and elevation difference through the system, while the dynamic head, $\mathrm{H}_{\mathrm{dyn}}(\mathrm{m})$, represents losses that are dependent on the flow rate. Equation 7 states that the pump's point of operation occurs where the total head available from the pump, $\mathrm{H}_{\text {available }}(\mathrm{m})$, is equal to the total head required by the system, $\mathrm{H}_{\text {required }}(\mathrm{m})$. The required head is a sum of the static head and the dynamic head losses (Çengel and Cimbala 2014).

$H_{\text {available }}=H_{\text {required }}=H_{\text {stat }}+H_{\text {dyn }}$

$H_{\text {required }}=H_{p}+H_{I}+k Q_{w}{ }^{2}$

In GSHP systems, where groundwater is extracted and injected at equal depth the equation can be simplified to Eq. 8. $\mathrm{H}_{\mathrm{p}}(\mathrm{m})$ and $\mathrm{H}_{\mathrm{I}}(\mathrm{m})$ imply the pressure drop in the production well and the pressure increase in the injection well, respective$\mathrm{ly}$, and $\mathrm{k}$ is a combined friction coefficient for the other components in the system, such as the pipes, valves and the groundwater heat exchanger. If fouling develops in the system the friction coefficient $\mathrm{k}$ will increase and the groundwater flow rate, $\mathrm{Q}_{\mathrm{w}}$, must decrease to maintain the balance of Eq. 7. $\mathrm{H}_{\mathrm{P}}$ and $\mathrm{H}_{\mathrm{I}}$ are flow dependent, implying that fouling in the system leads to a change in the water level in the wells. Alternatively, if fouling occurs in the wells, the flow rate from the submersible pump will decrease. Thus, the performance of the submersible pump is a good indication of the overall performance of the system.

\section{Well performance and the effects of clogging and fouling}

The wells are the connection between the GSHP systems and the aquifer. A well's behavior is unique and controlled by the overall behavior of the aquifer and the submersible pump. Acknowledging that a description of many possible scenarios may be relevant, here we show only some generalized examples; for more examples, the reader is referred to Kruseman et al. (1990) and Banks (2012).

Most crucial is the distinction between a production well and an injection well and, because neighboring wells might influence each other, whether only a single well is active or whether multiple wells are active simultaneously. The typical behavior of a single production well is illustrated in Fig. 8. During pumping, the water level in the production well will suffer a drawdown caused by the loss of pressure inside the well. The surrounding 
groundwater flows in through the screen in response to this pressure drop. With time, a cone of depression develops around the well. The magnitude of the drawdown is a function of the pumping rate and of the hydraulic properties of both the soil and the well screen. During production, the pumping rate controls the drawdown by adjusting the speed of the pump motor, as shown for three different speeds in Fig. 8a. The maximum allowed drawdown is limited by the placement of the pump with respect to the water table. The limit is not stationary, but can fluctuate or change. A typical example is seasonal variations in the water table caused by variations in groundwater recharge throughout the year. Figure $8 b$ illustrates a difference in an aquifer's natural water table between the summer and the winter months (Norwegian climate); this difference in turn affects the maximum available drawdown in the well. Consequently, the maximum production capacity of the well might have seasonal limitations.

The drawdown in the production well, $\mathrm{H}_{\mathrm{P}}$ as a function of the pumping rate, $Q_{w}$, can be described by Eq. 9, where B, C and $\mathrm{P}$ are site-specific parameters for the well (Rorabaugh 1953). The parameters are identified by conducting a "stepdrawdown" test in the production well, by example, through the methods developed by Jacob (1947) and Rorabaugh (1953) (described in Kruseman et al. 1990). The stepdrawdown test involves pumping the well with a series of steps of increasing flow rates. Each flow rate induces a different magnitude of water level drawdown (Fig. 8a). The resulting drawdown of each step needs time to develop, and a minimum of $0.5-2 \mathrm{~h}$ is recommended for each step. Reliable interpretation of the test data often requires each step to be of equal duration, and a minimum of three steps are needed to identify the three unknown parameters in Eq. 9.

$H_{P}=B Q_{w}+C Q_{w}{ }^{P}$
Experiences from Norwegian domestic waterworks have shown that the results from step drawdown tests can give a good indication of the performance of the production well (Banks 1992). Assuming that the sediment and screen properties remain the same throughout the lifetime of the well, a second test of the well after some time should ideally yield equal parameters to those of the first test. However, if the parameters change with time, the test can indicate changes in the hydraulic properties of the well or changes in the hydraulic properties of the aquifer. In the case of mechanical, chemical or microbial fouling of the well, particles clog the well screen and pores in the soil that in turn induce increased friction to the groundwater flow. As a result, the $\mathrm{B}, \mathrm{C}$ and $\mathrm{P}$ parameters increase, with a corresponding increase of drawdown in the production well. A subsequent reduction of the flow rate follows as the submersible pump must maintain the balance of Eq. 7. A distinction between fouling of the screen and fouling of the aquifer is often relevant because each requires a different cleaning approach. Since both scenarios would result in increased drawdown in the production well, additional information from a nearby observation well is necessary to distinguish between the two. If the fouling is limited to the screen alone, the cone of depression surrounding the well will diminish due to the reduced flow rate through the sediments (Fig. 8c). However, if the sediments are affected, the cone of depression, in terms of pressure loss, should also increase around the well (Fig. 8d).

The typical behavior of a single injection well is similar to that of a single production well, but instead of a drawdown both the water level in the well and the sediments increase. The rise of the water level in the injection well, $\mathrm{H}_{\mathrm{I}}$, as a function of the injection rate, $\mathrm{Q}_{\mathrm{w}}$, can be described by Eq. 10, where D, E and I are site-specific parameters for the well. The parameters are identified by conducting the same step test

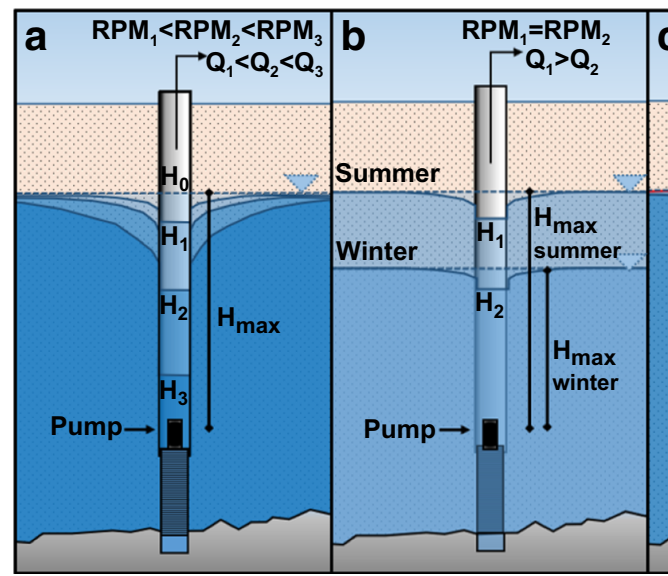

Fig. 8 Production well behavior with different pump speeds $\left(R P M_{x}\right)$. a Increased pumping rates $\left(Q_{I}-Q_{3}\right)$ induce increased drawdown in the well $\left(H_{1}-H_{3}\right)$ and in the aquifer. b Different maximum available drawdown in the summer $\left(H_{1}\right)$ and winter months $\left(H_{2}\right)$. c Local clogging or fouling of

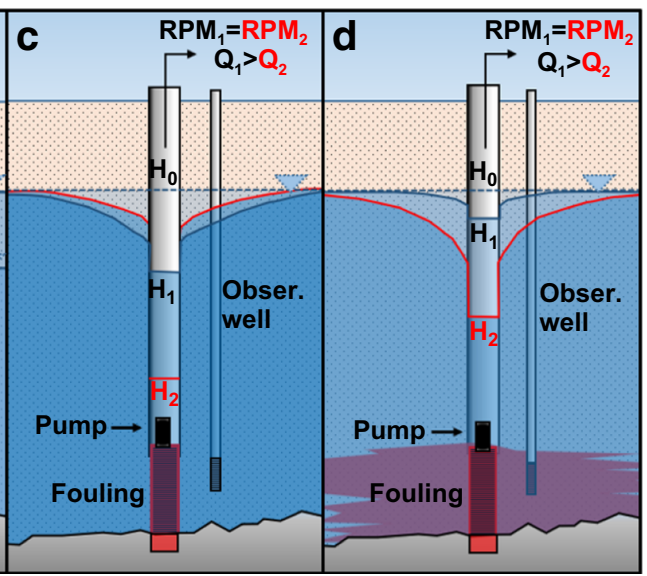

the well screen leads to increased drawdown in the well $\left(H_{1}-H_{2}\right)$, but reduced drawdown in the aquifer formation. $\mathbf{d}$ Clogging of the screen and deposition of the sediments lead to increased drawdown (pressure loss $)$ in the well $\left(H_{1}-H_{2}\right)$ and the aquifer formation 
as for the production well, but with the injection rate rather than the pumping rate.

$H_{I}=D Q_{w}+E Q_{w}{ }^{I}$

In an open loop GSHP system a minimum of two wells are often active at any given time: one production well and one injection well. In large installations, there might even be several production wells and injection wells in the same system; these are the so-called well fields (Banks 2012). Depending on the hydraulic properties of the sediments and the general behavior of the aquifer, these wells might influence each other in distinct ways. Figure 9 shows a typical example of where a well field of two production wells and two injection wells influence each other. In the production well field, both production wells induced additional drawdown in each other because they extract water from the same aquifer. A similar effect can be observed in the injection well field, but with an additional increase in water level. Additionally, the two well fields might interact across the aquifer. For example, the production wells could induce a drawdown in the injection wells and limit the increase in water level by a small amount and vice versa (Fig. 9). All of these influences affect the maximum production capacity of a well during operation.

The complexity of each individual well's behavior increases as more wells operate in the same aquifer. The overall well behavior of each individual well could include the well interaction effects by adding a series of sums into each individual equation. Banks (2012) suggested an approach that incorporates the Theis or Cooper-Jacob approximations for this purpose. As an alternative to this approach, the step test analysis described earlier can be applied to drawdown data of neighboring wells and added in Eqs. 9 and 10 for each well, for example as in Eqs. 11 and 12.
$H_{P}=B Q_{w}+C Q_{w}{ }^{P}+\sum_{i=1}^{n}( \pm) A_{n} Q_{n}$

$H_{I}=D Q_{w}+E Q_{w}{ }^{I}+\sum_{i=1}^{n}( \pm) F_{n} Q_{n}$

Where $A_{n}$ and $F_{n}$ are site-specific and well-specific drawdown parameters, respectively, induced by each neighboring well. Thus, if the flow rate in a neighboring well is known, $\mathrm{Q}_{\mathrm{n}}$ $(1 / \mathrm{s})$, the additional drawdown in the well or increase in water level in the well can be estimated and accounted for in the overall well behaviors.

\section{Proposed surveillance sensors and surveillance procedure}

The main goal of the surveillance procedure is to discover if and identify where fouling or clogging is developing, without having to stop the heat pump or any of the other system components. Considering the system described in the previous sections, the main concern for the open loop system is to ensure adequate heat flow to the heat pump evaporator. This is ensured by maintaining a sufficiently high groundwater flow rate through the groundwater heat exchanger with a sufficiently high groundwater temperature that meets the heat demand in the building. Consequently, the main parameters that should be monitored are the groundwater flow rate, the secondary fluid flow rate and the temperature variations of the groundwater and the secondary fluid.

Figure 10 illustrates the minimum number of sensors required to describe the performance of the production well, the injection well, the aquifer locally, the submersible pump and the groundwater heat exchanger. With the correct pre-investigative procedure, it is possible to monitor the system behavior with four temperature sensors, T1, T2, T3 and T4, and two pressure sensors, $\mathrm{p} 1$ and $\mathrm{p} 2$. The temperature sensors identify the heat
Fig. 9 Individual wells can influence neighboring wells. This becomes an issue in large well fields, where multiple wells operate simultaneously. Production wells induce increased water level or pressure drawdown, while injection wells induce an increase in the water level or pressure in nearby wells

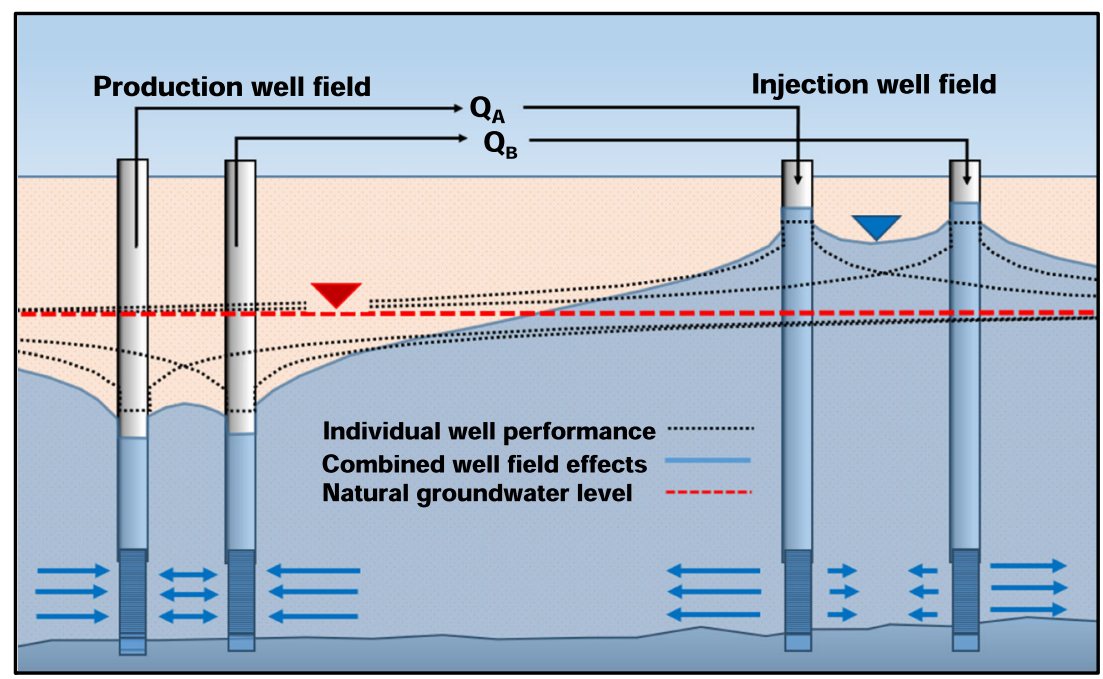




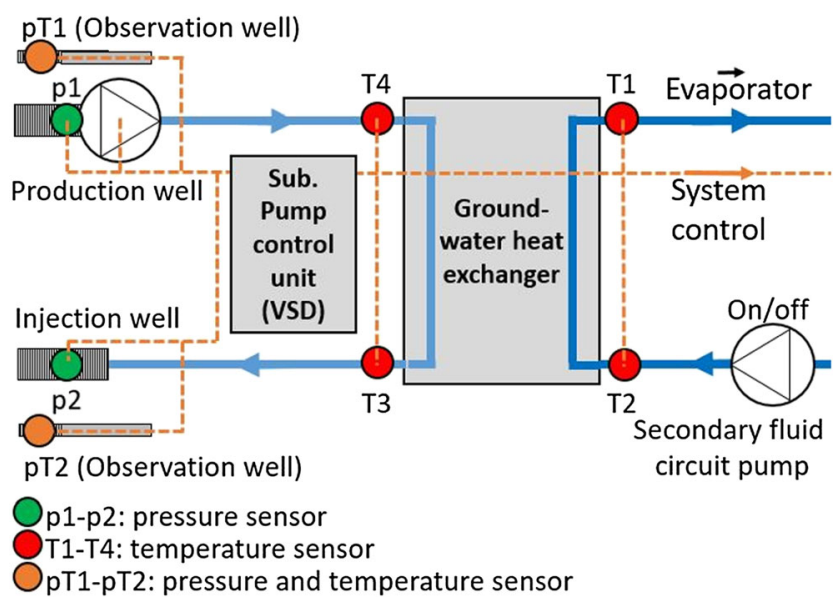

Fig. 10 Proposed surveillance sensors. The temperature sensors (T1-T4) combined with pressure sensors $(p 1-p 2)$ in the wells allow detection of fouling and clogging in the groundwater circuit. The pressure and temperature sensors in the observation wells ( $p T 1$ and $p T 2)$ supply additional information on the local aquifer conditions in near proximity to the respective wells

exchanger performance. The pressure sensors are required to identify the well performance with respect to the groundwater flow rate. Additionally, the pT1 and pT2 sensors (pressure and temperature) are necessary to distinguish variations in the the system from those in the local aquifer. All sensors are connected to the overall system control unit. The function and purpose of each sensor are described in Table 1.

Figure 10 does not include volume flowmeters. The proposed sensors (T1-T4) can estimate the groundwater flow rate by rearranging Eqs. 1 and 2 to Eq. 13. In the presented system design, the secondary fluid flow rate, $\mathrm{Q}_{\mathrm{sf}}$, is constant, and if $\Delta \mathrm{T}_{\mathrm{w}}$ and $\Delta \mathrm{T}_{\mathrm{f}}$ are sufficiently small to ensure limited variations in the volumetric heat capacities $\left(\rho \mathrm{C}_{\mathrm{Psf}}\right.$ and $\left.\rho \mathrm{C}_{\mathrm{Pw}}\right)$, the only variables on the right hand side are the fluid temperatures.

$Q_{w}=\frac{\Delta T_{s f}}{\Delta T_{w}} \cdot \frac{Q_{s f} \cdot \rho C_{P s f}}{\rho C_{P w}}$

Through Eqs. 6 and 13, the proposed temperature sensors allow surveillance of the groundwater flow rate and heat extraction rate from the groundwater. In open loop systems without VSD control the heat flow rates and volume flow rates are determined by the system characteristics only, and continuous surveillance of $\mathrm{p} 1, \mathrm{p} 2, \mathrm{Q}_{\mathrm{w}}$ and U.A should be sufficient for the detection of fouling. However, with VSD control these rates are often highly variable because of the applied control strategy. To distinguish any performance changes in a given component from one time to another it is necessary to follow a distinct procedure that describes the system performance from a known point of reference. One point of reference is the speed (RPM) of the submersible pump motor.

A testing procedure, similar to the well capacity test of Jacob (1947) and Rorabaugh (1953), can be conducted during normal system operation. During the test, the performance of the submersible pump, the groundwater heat exchanger, the production well and the injection well are identified at different groundwater flow rates. A minimum of three different speeds are necessary to estimate the unknown parameters in Eqs. 6, 8, 9 and 10. More steps will provide a higher accuracy in the estimates. Typically, the minimum RPM (or Hz) will function as the first step and the maximum RPM (or Hz) will function as the last step. Any number of additional steps should be selected between these two speeds at regular intervals (Fig. 11). Each step must be of equal duration and last between 0.5 and $2 \mathrm{~h}$.

A test conducted when the open loop GSHP system is new will provide data describing the initial system performance and function as a baseline for the initial capacity of the open loop GSHP system (Figs. 6, 11). Later, a second test with the same RPM settings might show a change in the system performance from the initial test and possibly a reduction of the system capacity, such as the red curves in Fig. 11. Eventually, the system characteristics might change so much that the original control strategy or open loop system design is predisposed to failure. Figure 11 illustrates some suggestions of failure modes, such as the reliable operation range for the submersible pump, possible flooding risks around the injection well or air mixing risk in the production well.

The test should also take into account the seasonal water level and temperature variations in the aquifer. Nearby observation wells can supply this information, which is useful when determining the maximum limits for both the production well and the injection well at different seasons. One example might be the summer and the winter limits shown in Fig. 11.

\section{Discussion}

System performance analysis through pressure, flow rate, and temperature parameters is a classical detection method in a wide range of different heat exchanger applications. There are alternative methods for the detection of heat exchanger fouling, but these generally involve the use of specialized fouling equipment, such as ultrasonic acoustics or electrical probes (Wallhäußer et al. 2013). Such methods have been developed for heat exchangers and pipes and are not necessarily applicable for use in groundwater wells. Therefore, the open loop GSHP wells would have to be subjected to individual tests. From an operator's point of view, it is beneficial to have a surveillance procedure that can detect faults in the whole heat source system. In this framework, the step-test performance analysis method is a good approach because it combines the well performance tests and heat exchanger performance test into a single test.

The system performance will show similarly symptoms regardless of the cause of the clogging. Thus, system 
Table 1 Description of the surveillance sensors

\begin{tabular}{|c|c|c|c|}
\hline Sensor & Monitoring function & Main purpose & Additional purpose \\
\hline T1 & $\begin{array}{l}\text { Secondary fluid return } \\
\text { temperature to the evaporator. }\end{array}$ & \multirow{4}{*}{$\begin{array}{l}\text { - Input to Eq. 13, these sensors allow } \\
\text { continuous estimation of } \mathrm{Q}_{\mathrm{w}} \text {. } \\
\text { - Input to Eq. } 6 \text {, these sensors allow } \\
\text { continuous monitoring of } \mathrm{U} \cdot \mathrm{A} \text { - } \\
\text { value. } \\
\text { - Allow calculation of energy output } \\
\text { from the aquifer. } \\
\text { - Calculation of COP if additional } \\
\text { information from the heat pump is } \\
\text { available. }\end{array}$} & \multirow{2}{*}{$\begin{array}{l}\text {-supply information } \\
\text { about the working } \\
\text { conditions for the } \\
\text { evaporator. }\end{array}$} \\
\hline $\mathbf{T 2}$ & $\begin{array}{l}\text { Secondary fluid temperature } \\
\text { from the evaporator. }\end{array}$ & & \\
\hline T3 & $\begin{array}{l}\text { Return temperature of the } \\
\text { groundwater before injection. }\end{array}$ & & $\begin{array}{l}\text {-Indicates risk of } \\
\text { groundwater freezing in } \\
\text { the heat exchanger. } \\
\text {-system control }\end{array}$ \\
\hline T4 & $\begin{array}{l}\text { Groundwater temperature from } \\
\text { the production well. }\end{array}$ & & $\begin{array}{l}\text { Indicates risk of thermal } \\
\text { short-circuiting in the } \\
\text { aquifer }\end{array}$ \\
\hline p1 & $\begin{array}{l}\text { Water level in the production } \\
\text { well. }\end{array}$ & $\begin{array}{l}\text { Input to Eq. } 9 \text { this sensor allow } \\
\text { operator to test well performance } \\
\text { and discover well clogging. }\end{array}$ & $\begin{array}{l}\text {-Indicates risk of air } \\
\text { mixing into the system. } \\
\text {-system control. }\end{array}$ \\
\hline p2 & $\begin{array}{l}\text { Water level in the injection } \\
\text { well. }\end{array}$ & $\begin{array}{l}\text { Input to Eq. } 10 \text { this sensor allow } \\
\text { operator to test well performance } \\
\text { and discover well clogging. }\end{array}$ & $\begin{array}{l}\text {-Indicates risk of surface } \\
\text { flooding. } \\
\text {-system control. }\end{array}$ \\
\hline pT1 & $\begin{array}{l}\text { Water level and temperature in } \\
\text { the aquifer close to the } \\
\text { production well. }\end{array}$ & $\begin{array}{l}\text {-Distinguish seasonal changes in the } \\
\text { aquifer from changes in the } \\
\text { production well water level. } \\
\text {-Discover clogging in the aquifer. }\end{array}$ & $\begin{array}{l}\text { - Indicates influence of } \\
\text { other nearby wells. } \\
\text { - Indicates risk of thermal } \\
\text { short-circuiting in the } \\
\text { aquifer. }\end{array}$ \\
\hline pT2 & $\begin{array}{l}\text { Water level and temperature in } \\
\text { the aquifer close to the injection } \\
\text { well. }\end{array}$ & $\begin{array}{l}\text {-Distinguish seasonal changes in the } \\
\text { aquifer from changes in the injection } \\
\text { well water level. } \\
\text {-Discover clogging in the aquifer. }\end{array}$ & $\begin{array}{l}\text { Indicates influence of } \\
\text { other nearby wells. }\end{array}$ \\
\hline
\end{tabular}

$\mathrm{Q}^{\mathrm{w}}$, groundwater flow rate; $\mathrm{U} \cdot \mathrm{A}$ value, overall heat transfer coefficient of the heat exchanger $(\mathrm{U}) \cdot$ total heat transfer area in the heat exchanger $(A)$; COP, coefficient of performance

${ }^{\mathrm{a}} \mathrm{T} 1-\mathrm{T} 4$, Temperature sensors; $\mathrm{p} 1, \mathrm{p} 2$, pressure sensors; $\mathrm{pT} 1, \mathrm{pT} 2$ pressure and temperature sensors

performance analysis allows for a general approach to system surveillance and is a suitable tool for all clogging problems. This flexibility in applicability is an advantage for open loop GSHP systems because of the considerable challenge of eliminating all of the potential problems in the design phase of new projects. The method can function as a standardized procedure for system surveillance before an initial fault has taken place. If better methods exist for monitoring particular faults, these can replace the step-test for that particular situation from then on. Specialized fouling equipment can then be installed because it is actually needed - rather than as a precaution.

The proposed procedure and sensors do not identify the cause of the clogging problem. However, by identifying which of the four major components that are affected, the test results enable the operator to plan necessary maintenance to the affected components without having to spend time on unaffected parts of the system. The cause of the problem can then be identified through other means, such as by video inspection of the affected wells or pipes (Gjengedal et al. 2018). Furthermore, the operator is able to investigate how effective the maintenance has been by conducting the same test procedure after the maintenance and comparing the results.
The procedure does not necessarily rely on an initial investigation of the system to work, but the behavior of the initial system provides a point of reference for future tests. The initial investigation would essentially confirm if the open loop GSHP system performs as well as the required specifications agreed upon in the tender document. Thus, the initial test should be part of the overall commissioning test of the system before the heat pump system is deemed finalized and handed over to the building owner.

The procedure in itself only involves incremental adjustments of the speed of the submersible pump motor. While these adjustments should be easy to conduct, data interpretation may be a challenge for the system operator. A key success factor in the surveillance procedure will be the pre-processing of the data in the system control unit. The data from the sensors shown in Fig. 10, the groundwater flowmeter measurements (FL in Fig. 3) or flow rate estimates $\left(\mathrm{Q}_{\mathrm{w}}\right.$ in Eq. 13) and the estimated $\mathrm{U} \cdot \mathrm{A}$ value should be presented on a control display in the machinery room as numbers and with the system limits visible as guidance.

Supervision and input from a specialist is probably necessary in most cases. Hydrogeological expertise is essential for 


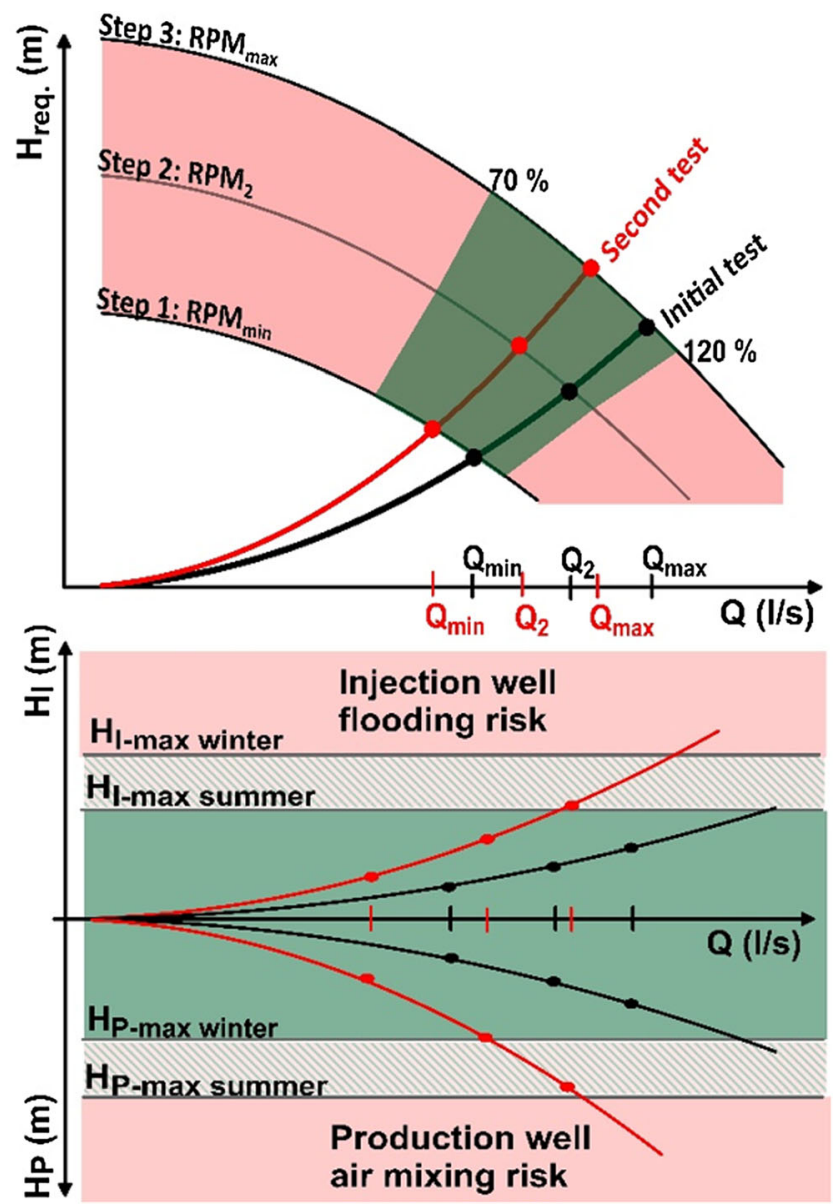

Fig. 11 Systemized "step-test" data with initial test shown as the black curve. A second test might detect fouling effects, which could result in the red curves. Green zones indicate areas of safe operation, while red zones indicate areas of unreliable operation where the system is predisposed to failure. RPM Rotational speed of the submersible pump motor (in $\mathrm{Hz}$ )

the interpretation of aquifer data and production well and injection well data and for the establishment of limitations to the aquifer system as a whole. Such expertise is especially essential in complex open loop GSHP systems, such as installations with multiple wells in multiple well fields, where the individual well performances might be difficult to identify due to well interaction effects. For small installations, such as those of $\leq$ $100 \mathrm{~kW}$, the cost of hiring a specialist on a regular basis might be an issue. However, the time needed to conduct the step-test will be within a single workday, on the scale of $3-8 \mathrm{~h}$ (per well doublet), and the test can be conducted during normal system operation without switching off the heat pump unit; both factors will limit the cost of the test. By allowing integrated remote control and monitoring of the GSHP system through an Internet Cloud solution, a specialist would be able to follow the test on-line without having to visit the installation. This might help minimize the cost of routine surveillance over longer periods.

The cost and stability of the sensors are important concerns to consider, as well as their degree of sensitivity and reliability.
The proposed number of pressure and temperature sensors in Fig. 10 is the minimum that enables full system surveillance of the system components highlighted in the figure and illustrates the least expensive solution. Additional sensors can and sometimes should be included, for example, a volume flowmeter or additional pressure sensors along the groundwater pipeline; however, these will increase the overall cost of the surveillance system and might not be deemed necessary in smallcapacity installations (e.g. $\leq 100 \mathrm{~kW}$ ). In large-capacity installations the number of sensors needed increase proportionally with the number of wells and heat exchangers, respectively. However, temperature and pressure sensors have multiple purposes in open loop GSHP systems (Table 1), and some sensors are also likely to be included in the system design and control strategy. By utilizing the same sensors for fouling and clogging detection, the initial investment cost for the procedure is reduced.

The key parameter in the surveillance strategy is the groundwater flow rate through the system $\left(\mathrm{Q}_{\mathrm{w}}\right)$. A direct measurement of the flow is favorable. However, a potential problem offered by water quality issues can complicate the matter if fouling affects the flow-measuring devices and leads to incorrect flow rate measurements. This could for example, occur when fouling forms on a pipe section where the flowmeasuring device is installed. In the surveillance procedure described herein, this potential problem is avoided by estimating the groundwater flow rate indirectly (Eq. 13). The accuracy of the estimate then relies on the accuracy of the temperature measurements. Proper mounting of the temperature sensors in probes inside the pipes, close to the heat exchanger entrances, in addition to proper calibration of the temperature sensors and the recording instruments are vitally important to ensure maximum accuracy (McMillan and Toarmina 2011). The temperature-estimated flow should be compared to a direct flow measurement by a portable flowmeter during the initial test to ensure accurate documentation of the sensor calibrations and flow rate estimate.

The accuracy of the estimate might still be insufficient for flow rate estimation if, for example, the $\Delta \mathrm{T}_{\mathrm{w}}$ and $\Delta \mathrm{T}_{\mathrm{sf}}$ are within the error range of the temperature sensors. For this reason, the recommended sensor types should have a small as possible error range (e.g. high-quality resistance thermometers $\left[\mathrm{Pt100 \textrm {A }}\right.$ ] with an error range $\pm 0.1-0.3{ }^{\circ} \mathrm{C}$ ). The $\Delta \mathrm{T}_{\mathrm{w}}$ and $\Delta \mathrm{T}_{\mathrm{sf}}$ can become an issue, for example, when the flow rates are high relative to the heat demand in the building. A possible solution for the problem would then be to control (VSD) the submersible pump to ensure a $\Delta \mathrm{T}_{\mathrm{w}}$ of at least $3^{\circ} \mathrm{C}$, which would limit the error in the estimated flow rate.

The indirect flow rate estimate depends on a temperature difference through the heat exchanger and works for both heating and cooling modes. However, even though the submersible pump and the secondary fluid circulation pump 
operate at constant flow rates during each step of the test, the heat rate through the groundwater heat exchanger might not have a constant rate and consequently might not operate at steady state. This can pose a problem for both the groundwater flow rate estimation and the U.A value estimation. This issue is discussed by Jonsson et al. (2007) and solved by introducing a physical state space model for on-line fouling detection in heat exchangers during normal system operations (transient time states). The implementation of an extended Kalman filter algorithm by these authors shows promising results. Combining their method with the step-test procedure might solve the parameter estimation issues.

Finally, the groundwater flow rate cannot be estimated via the temperature sensors if there is no heating or cooling demand in the building. In a typical Norwegian open loop GSHP system there is only a heating demand during the early spring, the late autumn and through the winter months. If there is no cooling demand in the building during the summer, a flowmeter is essential and must be installed for testing of the system in the summer. Open loop GSHP systems that have heating and/or cooling needs all year round can manage with the sensors in Fig. 10.

The main purpose of the proposed surveillance scheme is to monitor the system performance in relation to clogging issues. However, if the data from the sensors are recorded and stored, they also supply important information and documentation that describe hydraulic and thermal development in the aquifer over time. For example, it should be possible to draw conclusions regarding excessive heat extraction from the aquifer by assessing conditions detectable by the temperature sensors $\mathrm{T} 4, \mathrm{pT} 1$ and $\mathrm{pT} 2$ in relation to the injection temperature T3. The pT1 and pT2 sensors in particular are useful for evaluating the local aquifer conditions at the installed location, while sensor T4 only describes an average temperature of the entire screened section of the well in the aquifer. If governmental agencies require such documentation, the surveillance scheme thus provides the GSHP plant owner with the most basic documentation regarding environmental impact issues, such as aquifer water level data, heat extraction/injection data or groundwater extraction data (in cases with no re-injection; Fig. 1a).

\section{Conclusions}

There is a need for fouling and clogging surveillance in open loop GSHP systems. Given that there is a heat flux through the groundwater heat exchanger, four temperature sensors, two pressure sensors and a specified "step-test" surveillance procedure allow monitoring of the system performance. The main benefits and drawbacks of the test procedure can be summarized as follows. The test:
- describes actual system performance and identifies if clogging has occurred in the production well, the injection well, the aquifer and the groundwater heat exchanger;

- measures if the system performs in accordance with the specifications agreed upon in the tender document and should be included as a standard commissioning procedure for groundwater heat pump systems;

- can be conducted within a single workday (3-8 h per well doublet) and without disrupting the heat production in the heat pump;

- can investigate the effectiveness of normal maintenance procedures;

- requires low-cost sensors, but relies on accurate temperature and pressure measurements;

- does not identify the clogging type or clogging cause.

Data interpretation might be a challenge due to system and aquifer complexity. The pre-processing of data in the system control unit might ease the data interpretation process, but supervision and input from a specialist will normally be necessary.

Further work will be to test the procedure on an active open loop GSHP installation with clogging or fouling issues. The possibility of implementing a Kalman filter algorithm in the data pre-processing procedure to improve the estimates of both groundwater flow rate and the U.A-value should also be investigated.

Acknowledgments This work was conducted as a part of the research project Optimal Utilization of Groundwater for Heating and Cooling in Melhus and Elverum (ORMEL). The project is a cooperation between the municipalities of Melhus and Elverum, the Norwegian University of Science and Technology, Asplan Viak AS and the Geological Survey of Norway, and receives funding from the Regional Research Funds in MidNorway. We would like to thank all of the involved institutions and persons for cooperation and financial contributions. Special thanks to open loop GSHP operator Rolf Aune for all of the information and discussions about the installations in Melhus and to Associate Professor Jørn Stene at the Department of Energy and Process Engineering (NTNU) for pre-submission review and constructive comments.

Open Access This article is distributed under the terms of the Creative Commons Attribution 4.0 International License (http:// creativecommons.org/licenses/by/4.0/), which permits unrestricted use, distribution, and reproduction in any medium, provided you give appropriate credit to the original author(s) and the source, provide a link to the Creative Commons license, and indicate if changes were made.

\section{References}

Andersson A-C, Andersson O, Gustafson G (1984) Brunnar: undersökning, dimensionering, borrning, drift [in English: Wells: investigation, dimensioning, drilling, operation]. Statens råd för byggnadsforskning, Stockholm (in Swedish)

Atlas VH (2010) VDI heat atlas. Springer, Berlin Heidelberg 
Bakema G (2001) Well and borehole failures in UTESS. State of the art 2000, 2nd edn. IF Technology BV, Arnhem

Banks D (1992) Grunnvannsbrønner: kontroll, vedlikehold, rehabilitering [in English: Groundwater wells: control, maintenance, rehabilitation]. Norges Geologiske Undersøkelse, Trondheim (in Norwegian)

Banks D (2012) An introduction to thermogeology: ground source heating and cooling. Wiley-Blackwell, Chichester

Brøste HM (2017) Vannkvalitet knyttet til grunnvannsbaserte grunnvarmeanlegg i Melhus og Elverum [in English: Water quality with respect to open loop GSHP systems in Melhus and Elverum]. Norwegian University of Science and Technology (NTNU), Trondheim, Gjøvik, Ålesund (in Norwegian)

Çengel YA, Cimbala JM (2014) Fluid mechanics: fundamentals and applications. McGraw-Hill, Boston

Gjengedal S, Ramstad RK, Hilmo BO, Frengstad BS (2018) Video inspection of wells in open loop ground source heat pump systems in Norway. Editor: Prof. Jeffrey D. Spitler. International Ground Source Heat Pump Association, Oklahoma. In IGSHPA conferense proceedings 2018. https://doi.org/10.22488/okstate.18.000025

Gülich JF (2014) Centrifugal pumps, 3rd edn. Springer, Berlin Heidelberg

Hasan B, Jwair E, Craig R (2017) The effect of heat transfer enhancement on the crystallization fouling in a double pipe heat exchanger. Exp Thermal Fluid Sci 86:272-280

Jacob CE (1947) Drawdown test to determine effective radius of artesian well. Trans Am Soc Civ Eng 112(1):1047-1064

Jonsson GR, Lalot S, Palsson OP, Desmet B (2007) Use of extended Kalman filtering in detecting fouling in heat exchangers. Int $\mathrm{J}$ Heat Mass Transf 50:2643-2655

Kerner J (2011) Feature report compact, high-efficiency heat exchangers: understanding fouling. Chem Eng 118:35-41
Kruseman GP, Ridder NAD, Verweij JM (1990) Analysis and evaluation of pumping test data. International Institute for Land Reclamation and Improvement, Wageningen

Mackay R (2004) The practical pumping handbook. Elsevier, Oxford

McMillan GK, Toarmina CM (2011) Advanced temperature measurement and control. International Society of Automation

Melo LF, Bernardo CA, Bott TR (1988) Fouling science and technology. Kluwer, Dordrecht

Müller-Steinhagen H (2000) Heat exchanger fouling: mitigation and cleaning technologies : handbook. Publico Publications, Essen

Nema PK, Datta AK (2005) A computer based solution to check the drop in milk outlet temperature due to fouling in a tubular heat exchanger. J Food Eng 71:133-142

Rees S (2016) Advances in ground-source heat pump systems. Woodhead Publishing, Amsterdam

Riise MH (2015) Praktisk guide for grunnvarmeanlegg basert på oppumpet grunnvann-Hydrogeologiske forundersøkelser, etablering, drift og oppfølging med utgangspunkt i erfaringer fra etablerte anlegg i Melhus sentrum [in English: Guide to the open loop GSHP systems in Melhus]. Norwegian University of Science and Technology (NTNU), Trondheim, Gjøvik, Ålesund (in Norwegian)

Rorabaugh MJ (1953) Graphical and theoretical analysis of stepdrawdown test of artesian well. Proc Am Soc Civ Eng 79(12):1-23

Stene J (2001) Varmepumper: grunnleggende varmepumpeteknikk [in English: Heat pumps: basics] Trondheim, SINTEF Energi

von Böckh P, Wetzel T (2012) Heat transfer: basics and practice. Springer, Berlin Heidelberg

Wallhäusser E, Hussein MA, Becker T (2013) Clean or not clean - detecting fouling in heat exchangers, Editor, Professor Dr. Gerald Gerlach, AMA Association, Dresden, pp. 121-125. AMA Conferences 2013 - Proceeding of Sensor 2013, ISBN 978-39813484-3-9 